\title{
Otitis externa in a tertiary care hospital in Zagazig, Egypt: isolated pathogens and their antibiotic sensitivity patterns
}

\author{
${ }^{1 * A l l a m}$, A. A. E., ${ }^{2}$ Tantawy, A. E. E., ${ }^{2}$ Mohamed, K. A. E., ${ }^{3}$ El ghamrey, N. A. M., \\ ${ }^{1}$ Morad, E. A., and ${ }^{1}$ El Shafei, M. A. E. \\ ${ }^{1}$ Medical Microbiology and Immunology Department, Faculty of Medicine, Zagazig University, Egypt \\ ${ }^{2}$ ENT Department, Faculty of Medicine, Zagazig University, Egypt \\ ${ }^{3}$ ENT specialist, Egypt Ministry of Health and Population \\ *Correspondence to: Egyayman66@yahoo.com; +20155777174, +201227989609
}

\begin{abstract}
:
Introduction: Recurrent otitis externa is a worldwide problem. This study aims to identify the different aetiological organisms isolated from otitis externa and their sensitivity to different antibiotics.

Methods: A total of 27 patients with clinical presentation of otitis externa for a period of three weeks or more were enrolled for the study. Two swab samples collected from each infected ear were cultured for bacterial and fungi, and growth identified using standard microbiological methods including analytical profile index (API) system. Antibiotic susceptibility of isolated bacteria was performed by the disk diffusion technique.

Results: Thirty one organisms were isolated from the 27 patients; $12(38.7 \%)$ fungi and $19(61.3 \%)$ bacteria species. Aspergillus spp was the most frequently isolated organism (35.4\%) while Pseudomonas aeruginosa was the most frequently isolated bacteria $(19.3 \%)$, and was most sensitive to amikacin. Four of 11 patients with Aspergillus infection showed clinical resistance to econazole local treatment but had complete clinical response to itraconazole oral treatment.

Conclusion: Otitis externa in Egypt is caused by antibiotic resistant bacteria or fungi, and the most causative organisms are Aspergillus spp and Ps. aeruginosa.
\end{abstract}

Keywords: Otitis externa, antibiotic resistance, Pseudomonas aeruginosa, Egypt

Received June 25, 2019; Revised September 3, 2019; Accepted September 19, 2019

Copyright 2020 AJCEM Open Access. This article is licensed and distributed under the terms of the Creative Commons Attrition 4.0 International License (http://creativecommmons.org/licenses/by/4.0), which permits unrestricted use, distribution and reproduction in any medium, provided credit is given to the original author(s) and the source.

\section{Otite externe à I'hôpital de soins tertiaires de Zagazig, en Égypte: agents pathogènes isolés et leur profil de sensibilité aux antibiotiques}

\author{
${ }^{1 * A}$ Allam, A. A. E., ${ }^{2}$ Tantawy, A. E. E., ${ }^{2}$ Mohamed, K. A. E., ${ }^{3}$ El ghamrey, N. A. M., \\ ${ }^{1}$ Morad, E. A., et ${ }^{1}$ El Shafei, M. A. E.
}

${ }^{1}$ Département de microbiologie médicale et d'immunologie, Faculté de médecine, Université de Zagazig, Égypte ${ }^{2}$ Département d'ORL, Université de Zagazig, Faculté de médecine, Égypte ${ }^{3}$ spécialiste ENT, Ministère égyptien de la santé et de la population *Correspondance à:Egyayman66@yahoo.com; +20155777174, +201227989609

\begin{abstract}
Abstrait:
Introduction: L'otite externe récurrente est un problème mondial. Cette étude vise à identifier les différents organismes étiologiques isolés d'une otite externe et leur sensibilité à différents antibiotiques.

Méthodes: Un total de 27 patients présentant une présentation clinique de l'otite externe sur une période de trois semaines ou plus ont été inclus dans l'étude. Deux échantillons de prélèvement prélevés sur chaque oreille infectée ont été mis en culture pour détecter la présence de bactéries et de champignons, et leur croissance a été identifiée à l'aide de méthodes microbiologiques standard, notamment d'un système d'indice de profil analytique (API). La
\end{abstract}


sensibilité aux antibiotiques de bactéries isolées a été réalisée par la technique de diffusion sur disque. Résultats: Trente et un organismes ont été isolés parmi les 27 patients; 12 espèces de champignons (38,7\%) et 19 espèces de bactéries (61,3\%). Aspergillus spp était l'organisme le plus fréquemment isolé (35,4\%), tandis que Pseudomonas aeruginosa était la bactérie la plus fréquemment isolée $(19,3 \%)$ et était la plus sensible à l'amikacine. Quatre des 11 patients infectés par Aspergillus ont présenté une résistance clinique au traitement local à l'éconazole, mais ont présenté une réponse clinique complète au traitement oral à l'itraconazole.

Conclusion: L'otite externe en Egypte est causée par une bactérie ou un champignon résistant aux antibiotiques. Les organismes les plus responsables sont Aspergillus spp et Ps. aeruginosa.

Mots-clés: otite externe, résistance aux antibiotiques, Pseudomonas aeruginosa, Égypte

\section{Introduction :}

Otitis externa, also known as external otitis or swimmer's ear, is an inflammation of the pinna and external ear canal (1). Swimming in polluted water is a common means by which swimmer's ear is contracted but it is also possible to contract the disease from water trapped in the ear canal after a shower, especially in a humid climate. In addition to the presence of microorganisms, impairment of the integrity of the skin of the ear canal is required for external otitis to develop (2). Acute otitis externa is usually caused by bacteria while fungal involvement is commoner with chronic otitis externa.

Otitis externa is one of the most commonly encountered diseases by otorhinolaryngologists, and is common in certain parts of world with hot humid climate. Due to humid climate of Egypt, there is a high occurrence of otitis externa, especially in the summer. A number of patients are seen without evidence of eczematoid-type chronic otitis externa or other clear-cut causes of their recurrent bouts of otitis externa (3).

Although, the course of the disease is usually self-limited and responds quickly to basic treatment, some cases of otitis externa become resistant or are associated with multiple recurrences. This study aims to identify the microbial pathogens of otitis externa and determine their susceptibility to different antibiotics.

\section{Materials and method:}

\section{Study setting and design}

This cross sectional study was conducted at the Otorhinolaryngology Department of Zagazig University Hospital and Medical Microbiology and Immunology Department, Faculty of Medicine, Zagazig University, Egypt. The subjects included 27 patients with clinical diagnosis of otitis externa, who were enrolled among those attending the outpatient clinic on complaints of otitis externa for a period of three weeks or more, irrespective of previous therapy. The
Institutional Review Board of Faculty of Medicine, Zagazig University approved the study. Informed consent of each patient was obtained prior to enrollment.

\section{Clinical features of subjects}

Each patient had full medical history including duration of illness, symptoms and history of previous treatment, and a general examination. The patient ears were then examined after thoroughly dry-mopping with cotton pads, and signs such as tenderness, erythema, scales, exfoliation and ear discharge were recorded.

\section{Specimen collection and culture isolation}

Two swab samples were collected from each infected ear, one swab for bacterial culture and antibiotic susceptibility, and the other for fungal culture. The swabs were rapidly transferred to laboratory within one hour. For bacterial isolation, swab specimens were cultured on Blood, Chocolate and MacConkey agar plates. The Chocolate agar plate was incubated in candle extinction jar while the Blood and MacConkey agar plates were incubated in air. All media were incubated at $37^{\circ} \mathrm{C}$ for 48 hours. For fungi isolation, swab specimens were inoculated on two plates of Sabouraud Dextrose agar (SDA), one plate was incubated at $25^{\circ} \mathrm{C}$ (room) temperature and the other at $37^{\circ} \mathrm{C}$ for 14 days.

\section{Microbial identification from culture}

Isolated bacteria were identified according to standard bacteriology techniques of Gram stain, colony morphology and biochemical reactions including the API system (4). Antibiotic susceptibility test was performed by the disc diffusion method and interpreted according to Clinical and Laboratory Standards Institute (CLSI) guidelines (5). Filamentous fungi isolated were identified using modified slide culture technique (6) while Candida albicans was identified by the germ tube test.

\section{Modified slide culture technique:}

A 1 by $1 \mathrm{~cm}$ block of SDA was cut with sterile scalpel and transferred to a plate of SDA. The isolated fungus was inoculated using 
sterile wire needle into the four sides of the agar block. Sterile cover slip was put over the block with slight pressure to ensure adherence and the plate cover replaced afterwards. The plates were incubated at $25^{\circ} \mathrm{C}$ (room temperature). The growth of the fungus was examined periodically. The closed Petri dish was placed on the microscope stage and the slide culture examined with the low power. When reproduced structures had developed, a forcep was used to remove the cover slip and put on a second slide for examination. The agar block was removed using flamed wire needle and put into a container of antifungal disinfectant. A drop of Lactophenol cotton blue stain was put on the remaining slide and was then covered with a new cover slip (6).

\section{Therapy and follow up of patients:}

Patients were treated with appropriate antibacterial and antifungi agents, and followup visit was at the seventh day after the baseline visit. Treatment was continued for patients whose symptoms persist with followup visits at 2 and 3 weeks. At each follow up, clinical information such as pain, itching, otorrhoea, stuffy feeling, burning, irritation and compliance with treatment were obtained from patients and recorded.

\section{Results:}

The study was conducted on 27 patients with clinical otitis externa, 18 males and 9 females ( $M$ : $F$ ratio of $2: 1$ ). The age range of the subjects was $15-64$ years with mean of $42.37 \pm 14.01$. Table 1 summarizes the demographic characteristics and clinical manifestations of the patients.

Table 2 shows that 31 organisms were isolated from the patients; 12 (38.7\%) fungi and 19 (61.3) bacteria species. Aspergillus spp was the most frequently isolated organism (35.4\%). Bacteria isolated were 9 (29\%) Gram positive and 10 (32.3\%) Gram negatives. Pseudomonas aeruginosa was the most frequently isolated bacteria (19.3\%), followed by Staphylococcus epidermidis (16.1\%), Klebsiella spp (9.7\%) and Staphylococcus aureus (9.6\%). As shown in Table 3, there was no significant association between the types of microorganism isolated (bacteria or fungi) and symptoms of otalgia $(p=0.8137)$, itching $(p=0.7347)$ or ear discharge $(p=0.2522)$.

The antibiotic susceptibility of the Gram positive bacteria as depicted in Table 4 shows that they were mostly sensitive to ciprofloxacin, levofloxacin and linezolid, and resistant to clindamycin, tetracycline and ceftriaxone. The Gram negative bacteria were mostly sensitive to imipenem, levofloxacin, ciprofloxacin and colistin, and largely resistant to chloramphenicol, gentamicin, tobramycin and ceftriaxone.

Patients with Aspergillus infection $(n=11)$ were treated with econazole but only 7 had complete clinical response to econazole local treatment while the remaining 4 had complete clinical response to itraconazole oral treatment. The patients with Candida infection had clinical response to terbinafine cream.

Table 1: Socio-demographic characteristics and clinical history of patients with clinical otitis externa in Zagazig University Hospital, Egypt

\begin{tabular}{|c|c|c|}
\hline Characteristics & Frequency & Percentage \\
\hline \multicolumn{3}{|l|}{ Gender } \\
\hline Male & 9 & 33.3 \\
\hline Female & 18 & 66.7 \\
\hline \multicolumn{3}{|l|}{ Marital status } \\
\hline Married & 25 & 92.5 \\
\hline Single & 1 & 3.75 \\
\hline Widow & 1 & 3.75 \\
\hline \multicolumn{3}{|l|}{ Occupation } \\
\hline Employed & 13 & 48.2 \\
\hline Unemployed & 14 & 51.8 \\
\hline \multicolumn{3}{|l|}{ Smoking history } \\
\hline None & 21 & 77.8 \\
\hline Smokes & 6 & 22.2 \\
\hline \multicolumn{3}{|l|}{ Past medical history } \\
\hline No previous surgery & 14 & 51.8 \\
\hline Adenotonsillectomy & 1 & 3.75 \\
\hline Tonsillectomy & 2 & 7.5 \\
\hline Allergy from drugs & 1 & 3.75 \\
\hline Not relevant & 9 & 33.3 \\
\hline \multicolumn{3}{|l|}{ Clinical manifestations } \\
\hline Otalgia & 26 & 96.3 \\
\hline Discomfort & 22 & 88.5 \\
\hline Itching & 26 & 96.3 \\
\hline Edema of ear canal & 27 & 100 \\
\hline
\end{tabular}


Table 2: Microorganisms isolated from patients with otitis externa in Zagazig University Hospital, Egypt

\begin{tabular}{cccc}
\hline & Microorganism & Frequency & Percentage \\
\hline Fungi & Aspergillus spp & 12 & 38.7 \\
Candida spp & 11 & 35.4 & 3.2 \\
Gram positive bacteria & 1 & 29 & 3.2 \\
Diphtheroids & 9 & 9.6 & 16.1 \\
Staphylococcus aureus & 1 & 32.3 \\
Staphylococcus epidermidis & 3 & 19.3 \\
Gram negative bacteria & 5 & 9.7 & 3.2 \\
Pseudomonas aeruginosa & 10 & 6 & 100 \\
Klebsiella spp & 3 & 1 & \\
Proteus spp & 31 & & \\
Total & &
\end{tabular}

Table 3: Relationship between symptoms of otitis externa and microorganisms isolated among patients in Zagazig University Hospital, Egypt

\begin{tabular}{|c|c|c|c|c|c|c|}
\hline \multirow[t]{2}{*}{ Symptoms } & \multicolumn{3}{|c|}{ Microorganism } & \multirow[t]{2}{*}{$x^{2}$} & \multirow{2}{*}{$95 \% \mathrm{CI}$} & \multirow[t]{2}{*}{$p$ value } \\
\hline & $\begin{array}{c}\text { Bacteria } \\
(n=19)\end{array}$ & $\begin{array}{c}\text { Fungi } \\
(n=12)\end{array}$ & $\begin{array}{c}\text { Total } \\
(n=31)\end{array}$ & & & \\
\hline \multicolumn{7}{|l|}{ Otalgia } \\
\hline Positive & 19 & 11 & 30 & 0.05552 & $0.4385-0.8005$ & $0.8137 *$ \\
\hline Negative & 0 & 1 & 1 & & & \\
\hline \multicolumn{7}{|l|}{ Ear discharge } \\
\hline Positive & 10 & 3 & 13 & 1.311 & $0.8878-2.666$ & $0.2522 *$ \\
\hline Negative & 9 & 9 & 18 & & & \\
\hline \multicolumn{7}{|l|}{ Ear itching } \\
\hline Positive & 18 & 11 & 29 & 0.1149 & $0.3015-5.111$ & $0.7347^{*}$ \\
\hline Negative & 1 & 1 & 2 & & & \\
\hline
\end{tabular}

Table 4: Antibiotic susceptibility profile of bacteria isolates of otitis externa in Zagazig University Hospital, Egypt

\begin{tabular}{|c|c|c|c|c|}
\hline \multirow[t]{2}{*}{ Antibiotics } & \multicolumn{2}{|c|}{ Gram positive bacteria $(n=9)$} & \multicolumn{2}{|c|}{ Gram negative bacteria $(n=10)$} \\
\hline & Sensitive (\%) & Resistant (\%) & Sensitive (\%) & Resistant (\%) \\
\hline Oxacillin & $1(11.1)$ & $8(88.9)$ & NA & NA \\
\hline Tetracycline & $1(11.1)$ & $8(88.9)$ & NA & NA \\
\hline Clindamycin & $1(11.1)$ & $8(88.9)$ & NA & NA \\
\hline Linezolid & $9(100)$ & 0 & NA & NA \\
\hline Chloramphenicol & NA & NA & 0 & $10(100)$ \\
\hline Tobramycin & NA & NA & $4(40)$ & $6(60)$ \\
\hline Amikacin & NA & NA & 7 (70) & $3(30)$ \\
\hline Colistin & NA & NA & $9(90)$ & $1(10)$ \\
\hline Aztreonam & NA & NA & $6(60)$ & $4(40)$ \\
\hline Amoxicillin-Clavulanic acid & $3(33.3)$ & $6(66.7)$ & $1(10)$ & $9(90)$ \\
\hline Ceftriaxone & $1(11.1)$ & $8(88.9)$ & $4(40)$ & $6(60)$ \\
\hline Gentamicin & $5(55.6)$ & $4(44.4)$ & $2(20)$ & $8(80)$ \\
\hline Ciprofloxacin & $9(100)$ & 0 & $9(90)$ & $1(10)$ \\
\hline Laevofloxacin & $9(100)$ & 0 & $9(90)$ & $1(10)$ \\
\hline Imipenem & $8(88.9)$ & $1(11.1)$ & $9(90)$ & $1(10)$ \\
\hline
\end{tabular}

NA $=$ Not Applicable

\section{Discussion:}

Otitis externa is a common disease and its severity varies from mild, self-limited condition to severe malignant otitis externa with involvement of cartilage and bone of the external auditory canal, and a tendency to break through to the brain (7). In the current study, Ps. aeruginosa was the most frequently isolated bacteria pathogen and constituted $19.5 \%$ of the isolates, which agrees with previous studies that established this pathogen as the most frequent in acute otitis externa (8, 9). The rate for Ps. aeruginosa in this study is however lower than $41.7 \%$ reported from a study conducted on ear discharge of malignant otitis externa in Jordan (10) and $52.9 \%$ in India (11), but the rate is higher than $12 \%$ reported from a study in Iran (12).

Among the fungi, Aspergillus spp are the predominant organisms implicated in otomycosis (7). In the current study, Aspergillus spp was the most frequently isolated organism with $35.4 \%$, which agrees with studies from 
Turkey (13) and Iran (14), where Aspergillus spp constituted $78.6 \%$ of otomycosis agents, followed by Candida species (6.8\%) and other saprophytic fungi $(4.7 \%)$. The high prevalence of fungal otitis externa may be secondary to over use of broad spectrum antibiotics and increased topical use of fluoroquinolones (13), which encourages fungi overgrowth.

Fungal otitis externa is often asymptomatic, with discomfort being the most frequent complaint, but there may be pruritus and a feeling of fullness in the ear. Aspergillus species, particularly Aspergillus niger may grow in the cerumen and desquamated keratinaceous debris in the external auditory canal, sometimes forming a visible greenish or blackish fluffy colony (6). In this study, there was no significant difference between the symptoms of otalgia, ear itching or discharge between bacteria and fungi otitis externa $(p>0.05)$.

In the current study, the Gram negative bacteria were mostly sensitive (90\%) to imipenem, laevofloxacin, ciprofloxacin and colistin, but largely resistant to chloramphenicol, gentamicin, tobramycin and ceftriaxone. The Gram positive bacteria on the other hand were totally sensitive $(100 \%)$ to laevofloxacin, ciprofloxacin and linezolid, and $89 \%$ sensitive to imipenem, but were largely resistant to clindamycin, tetracycline and ceftriaxone. The most frequently isolated Gram negative bacteria, Pseudomonas spp was mostly sensitive to amikacin, imipenem, laevofloxacin, ciprofloxacin and colistin, but largely resistant to amoxicillin-clavulanate, gentamicin, tobramycin and chloramphenicol. All $S$. aureus and $S$. epidermidis isolates were resistant to oxacillin, while the only diphtheroid was sensitive to the antibiotic. The issue of bacterial resistance to antibiotics is a global challenge (15). In developed countries such as the United States, contemporary ear culture isolates at quaternary care center show higher rates of methicillin resistant $S$. aureus (MRSA) compared to historical reports in the literature (16). However, the challenge of antibiotic resistance is more in developing countries such as Egypt (17), as a result of low socioeconomic state and behavioral pattern of the populace regarding antibiotic use (18). In Egypt, antibiotics can be purchased from pharmacies without medical authorization or prescription.

In this study, fungi were isolated in $38.7 \%$ of cases with half of them having bacteria pathogen concurrently involved, which explains the chronicity of the lesion. These cases were previously treated as pure bacterial infection while the fungal aetiology was hidden by the discharge and erythema usually seen in bacterial infection. On the other hand, fungal infection is usually associated with itching as seen in 11 out of $12(91.7 \%)$ cases in this study.

Treatment of acute otitis externa should include an active antimicrobial agent and not just an acidifying agent such as acetic acid (19). Moderate to severe cases will require ototopical agents in addition to antiseptic solution (20). Ciprofloxacin ear drop was the commonest agent used in the initial treatment of our patients followed by gentamicin with or without corticosteroid, and then econazole antifungal agent. Our study observed that many of the locally used drugs such as gentamicin, chloramphenicol and tetracycline have poor activity against most pathogens. This may be due to the injudicious use of these agents which has resulted in the emergence of more resistant strains, especially among the troublesome pseudomonads.

The resistant otitis externa cases could also be associated with contact dermatitis (7), therefore antiinflammatory corticosteroid combination in the ear drops may be required. In the case series by Smith et al., (21) in 1990, $23.5 \%$ of their patients with otitis externa had contact dermatitis, and this was even less than what Holmes and Johnson (22) had reported in 1982. Infestation by Demodex species can also cause persistent itching in resistant cases especially in immuno-compromised patients (23) or with prolonged use of local steroid which may increase the frequency of the parasite in the external ear canal of affected patients (24). In this study, local treatment of candida otitis externa was totally responsive to terbinafine cream but only 7 out of 11 patients with Aspergillus infection had complete clinical response to econazole local treatment. The four patients resistant to econazole had complete clinical response to itraconazole oral treatment. This observation agrees with a study in India (25), which reported that 5 days course of itraconazole treatment was very effective for recurrent otomycosis in diabetic patients.

\section{Conclusion:}

Our study reports that otitis externa in Egypt is caused by antibiotic resistant bacterial and fungi, the most common pathogens being Aspergillus spp and Ps. aeruginosa. Oral itraconazole was effective for recurrent fungal otitis externa. We recommend that in cases of otitis externa resistant to antibacterial agents, 
fungi aetiology should be investigated by culture on Saboraud Dextrose agar.

\section{Conflict of interest:}

Authors declared no conflict of interest

\section{Source of funding:}

Authors received no funding from any agency in the public, commercial, or not-forprofit sectors.

\section{Authors contributions:}

AAA, AEET and KAEM were responsible for concept and design of the study. NAME undertook acquisition and interpretation of data and drafting of the manuscript. All authors contributed to data collection. AAA undertook critical review of the manuscript. NAME, EAM and MAEE undertook statistical analysis and review of the manuscript.

\section{References:}

1. Moharram, A. M., Ahmed, H. E., and Nasr, S. A. M. Otomycosis in Assiut, Egypt. Journal of Basic and Applied Mycology (Egypt); 2013; 4: 1-11.

2. Roland, P. S., and Stroman, D. W. Microbiology of acute otitis externa. Laryngoscope. 2009; 112: 1166-1177. https://doi.org/10.1097/00005537-2002070 00-00005

3. Shapiro, D. P. Recurrent Otitis Externa. Arch Otolaryngol Head Neck Surg. 1989; 115 (3): 394 https://doi.org/10.1001/archotol.1989.01860270136034

4. Mackie, T. J., Collee, J. G., and McCartney, J. E. Mackie and McCartney Practical Medical Microbiology. New York: Churchill Livingstone, 1996.

5. Clinical and Laboratory Standards Institute (CLSI). Performance standards for antimicrobial disk susceptibility tests; 9th approved standard. Document M2-A9. Wayne, PA: CLSI; 2006.

6. Rosana, Y., Matsuzawa, T., Gonoi, T., and Karuniawati, A. Modified Slide Culture Method for Faster and Easier Identification of Dermatophytes. Microbiol Indonesia. 2014; 8: 135 - 139. https://doi.org/10.5454/mi.8.3.

7. Mustafa, M., Patawari, P., Sien, M. M., Muniandy, R. K., and Zinatara, P. Acute Otitis Externa: pathophysiology, clinical presentation, and treatment. IOSR Journal of Dental and Medical Sciences. 2015; 14: $73-78$

https://doi.org/10.9790/0853-14717378

8. Hajioff, D., and Mackeith, S. Otitis externa. Clinical Evidence. BMJ. 2015; 6 (51): 1 - 23.

9. Treviño González, J. L., and Moreno, K. D. Otitis Externa: an update. Ann Otolaryngol Rhinol. 2017; 4 (8): 1195

10. Battikhi, M. N., and Ammar, S. I. Otitis externa infection in Jordan. Clinical and microbiological features. Saudi Med J. 2004; 25 (9): 199 - 203.

11. Shamanna, K., and Ganga, B. V. Changing trend in the management of malignant otitis externa: our experience. Research in Otolaryngology. 2018; 7 (1): 9-14.

https://doi.org/10.5923/j.otolaryn.20180701.03
12. Kiakojuri, K., Mahdavi, O. S., Jalili, B., et al. Bacterial Otitis Externa in Patients Attending an ENT Clinic in Babol, North of Iran. Jundishapur J Microbiol. 2016; 9 (2): e23093. https://doi.org/10.5812/jim.23093.

13. Enoz, M., Sevinc, R., and Florencio Lapeña, J. Bacterial and fungal organisms in otitis externa patients without fungal infection risk factors in Erzurum, Turkey. Braz J Otorhinolaryngol. 2009; 75: 721 - 725. http://dx.doi.org/10.1590/S1808-86942009000500018

14. Gharaghani, M., Seifi, Z., and Mahmoudabadi, A. Z. Otomycosis in Iran: A Review. Mycopathologia. 2015; 179: 415-424. https://doi.org/10.1007/s11046-015-9864-7

15. Roca, I., Akova, M., Baquero, F., et al. The global threat of antimicrobial resistance: science for intervention. New Microbes and New Infections. 2015; 6: 22-29.

https://doi.org/10.1016/j.nmni.2015.02.007

16. Duarte, M. J., Kozin, E. D., Bispo, P. J. M., el al. Methicillin resistant Staphylococcus aureus in acute otitis externa. World J Otorhinolaryngol Head Neck Surg. 2018; 4: 246-252.

https://doi.org/10.1016/j.wjorl.2017.09.003

17. Ayukekbong, J. A., Ntemgwa, M., and Atabe, A. N. The threat of antimicrobial resistance in developing countries: causes and control strategies. Antimicrob Resist Infect Contr. 2017; 6: 47. https://doi.org/10.1186/s13756-017-0208-x

18. Okeke, I. N., Lamikanra, A., and Edelman, R. Socioeconomic and behavioural factors leading to acquired bacterial resistance to antibiotics in developing countries. Emerg Infect Dis. 1999; 5 (1):18-27. https://doi.org/10.3201/eid0501.990103

19. Dohar, J. E. Evolution of management approaches for otitis externa. Pediatr Infect Dis J. 2003; 22: 299-305.

https://doi.org/10.1097/01.inf.0000059444.02851.1e.

20. Osguthorpe, J. D., and Nielsen, D. R. Otitis externa. Review and clinical update. Am Fam Phys. 2006; 74 (9): 1510-1516.

21. Smith, I. M., Keay, D. G., and Buxton, P. K. Contact hypersensitivity in patients with chronic otitis externa. Clin Otolaryngol. 1999; 15: 155156. https://doi.org/10.1111/j.1365-2273.1990.tb00449.x

22. Holmes, R. C., Johns, A. N., Wilkinson, J. D., et al. Medicament contact dermatitis in patient with chronic inflammatory ear disease. J R Soc Med. $1982 ; 75$ (1): 27-30.

23. Bilal, N., Kirişci, Ö., and Özkaya, E. Demodex species infestation in patients with ear itching and its relationship to itch severity. Turkiye Parazitol Derg. 2017; 41: 87-91.

https://doi.org/10.5152/tpd.2017.5070

24. Cevik, C., Kaya, O., Akbay, E., et al. Investigation of Demodex species frequency in patients with a persistent itchy ear canal treated with a local steroid. J Laryngol Otol. 2014; 128 (8): 698-701. https://doi.org/10.1017/S0022215114001510.

25. Venkataramanan, R., and Kumar, R. S. Efficiency of 5 Day Course Oral Itraconazole in Management of Recurrent Otomycosis in Diabetic Patients-a Randomized Control Clinical Trial. Indian J Res. 2016; 5 (1): 96-98. 